\title{
Modeling Diffusivity Through Alginate-Based Microfibers: A Comparison of Numerical and Analytical Models Based on Empirical Spectrophotometric Data
}

\author{
Sabra Djomehri ${ }^{1}$, Maryam Mobed-Miremadi ${ }^{1, *}$ and Mallika Keralapura ${ }^{2}$ \\ ${ }^{1}$ Department of Biomedical, Chemical and Materials Engineering, San Jose State University, San Jose CA \\ 95192-0082, USA \\ ${ }^{2}$ Department of Electrical Engineering, San Jose State University, San Jose CA 95192-0082, USA
}

\begin{abstract}
The study of mass transport across hollow and solid 3D microfibers to study metabolic profiles is a key aspect of tissue engineering approach. A new modified numerical mathematical model based on Fickian equations in cylindrical coordinates has been proposed for determining the membrane diffusivity of $2 \%(\mathrm{w} / \mathrm{v})$ alginate-based stents cross-linked with $10 \% \mathrm{CaCl}_{2}$. Based on the economical and direct spectrophotometric measurements, using this model, inward diffusivities ranging from $5.2 \times 10^{-14} \mathrm{~m}^{2} / \mathrm{s} 2.93 \times 10^{-12} \mathrm{~m}^{2} / \mathrm{s}$ were computed for solutes with Stokes radii ranging between 0.36 to $3.5 \mathrm{~nm}$, diffusing through bare alginate and alginate-chitosan-alginate microfibers. In parallel an analytical solution to the cylindrical Fickian equation was derived to validate the numerical solution using experimental diffusion data from a solid stent. Excellent agreement was found between the numerical and analytical models with a maximum calculated residual value of $4 \%$. Using these models, a flexible computational platform is proposed to conduct custom diffusion and MW cut-off characterization across micro-porous microfibers not limited to alginate in composition.
\end{abstract}

Keywords: Alginate, diffusivity, modeling, hollow fiber, cylindrical.

\section{INTRODUCTION}

Modeling the diffusive behavior of polymeric materials is crucial for the development of several types of tissue engineering and drug delivery systems. Since mass transport phenomena will affect the function and efficacy of such systems, a quantitative basis for understanding diffusion characteristics is necessary. Systems that use cylindrical geometry for clinical applications could be hollow fibers or tubular stents [1-4]. These applications have previously focused on tubular prostheses for the purpose of repairing or dilating a lumen of the body, however, hollow fiber applications have since expanded into microencapsulation technology [5-7]. It is assumed that the hollow fiber membrane is semi-permeable to allow transfer of drugs or tissue fluids. Enclosing proteins, enzymes, or cells within a microfibers has gained significant potential in the biomedical realm, and can be used in cell-culture, microfluidic systems, scaffolding, hemodialysis, and as bioreactors for generating monoclonal antibodies, viruses/antigens, recombinant proteins, and viable cells [4, 6-8].

Current research efforts focus on using natural polymers such as alginate and chitosan for development of novel drug delivery systems for both

*Address correspondence to this author at the Department of Biomedical, Chemical and Materials Engineering, San Jose State University, San Jose CA 95192-0082, USA Tel: (408) 924 4003; Fax: (408) 924-4057;

E-mail: maryam.mobed-miremadi@sjsu.edu small (e.g. anti-inflammatory drugs) and large (e.g. peptides, proteins) molecules [7, 9-11]. Increasing interest has been placed on these hydrogels owing to their biocompatible, biodegradable, and non-toxic nature. The pore sizes in the gel network of hydrogels vary from macroporous $(0.1-1 \mu \mathrm{m})$ to microporous (10$100 \mathrm{~nm}$ ) [9]. Drugs embedded in the hydrogel matrix are released through these pores by a diffusion mechanism dependent on the diffusion coefficient of the polymer membrane. Diffusion through macroporous networks is affected by its porosity and tortuosity, while diffusion through microporous networks is dependent on diffusion and convection [7, 9, 12]. Non-porous hydrogel matrices release drugs by diffusion only.In this study, 1D numerical and analytical mathematical models were developed for determining the membrane diffusivity through solid and hollow alginate-based stents in order to generate profiles of mass transport for solute exchange. The use of Fickian modeling in conjunction with various experimental methods previously for tracking diffusion across spherical microcapsule membranes spectrophotometrically [1214] has been extended to cylindrical geometry. Using this approach, researchers in the fields of regenerative medicine and tissue engineering can simulate and validate radial micro-measurements related to intramembrane fluxes with ease and confidence, a potential example being clustering of metabolic trends by differentiation states.

Several established methods are currently used to measure pore sizes of cross-linked hydrogels namely 
laser interferometry, chromatographic breakthrough curves, fluorescence recovery after photobleaching (FRAP), scanning electron microscopy, atomic force microscopy, thermoporometry [15-18]. When comparing spectrophotometry to the other aforementioned analytical techniques, there are some important processing advantages that need to be addressed: 1) spectrophotometry is suited for laboratory measurements, requiring a single low maintenance piece of equipment; 2) the measurements are non-destructive as compared to the analytic methods requiring sample immobilization, morphology modifications and cross-sectioning introducing measurement artifacts; 3) this technique could be extended to miniaturized high-throughput spectrophotometric-based assays provided that the assay sensitivity is scaled adequately. With respect to the computational aspect, the closest existing models for the characterization of mass transfer across cylindrical structures are for drug eluting stents, combining diffusion and convection over a specific MW range of solutes restricted to drug delivery [19]. For custom membrane design formulations and MW cut-off determination sought in regenerative medicine, tissue engineering and drug delivery applications, the proposed forms of numerical and analytical solutions limited to diffusion can be adapted for use across multiple membrane mesh sizes and over a wider range of MW. In addition, the use of this model can be extended to non-alginate-based macro-porous microfibers in alignment with the emerging types of novel biomaterials.

\section{MATERIALS AND METHODS}

\section{Materials}

All materials used in this study were acquired from Sigma-Aldrich; these are: medium molecular weight sodium-alginate (A2033), low molecular weight sodiumalginate (A2158), low molecular weight chitosan (44,886-0.5\% deacetylated), polylysine-hydrobromide $20,000<M W<30,000$ (P81333). All other reagents were provided by the Chemistry store in the Faculty of Sciences at SJSU: creatinine powder (MW=113.2 Da), polyethylene glycol (PEG) powder (MW=3,500 Da and $6,000 \mathrm{Da})$, and bovine serum albumin (BSA, $\mathrm{MW}=64,000 \mathrm{Da})$.

\section{Methods}

\section{Solid Stent preparation}

A $2 \%(\mathrm{w} / \mathrm{v})$ or $3 \%(\mathrm{w} / \mathrm{v})$ alginate mixture was prepared by dissolving $2 \mathrm{~g}$ or $3 \mathrm{~g}$ of medium viscosity alginic acid into $100 \mathrm{~mL} 0.9 \%(\mathrm{w} / \mathrm{v}) \mathrm{NaCl}$ solution, respectively. The resultant alginate mixture was loaded into a $10-\mathrm{mL}$ syringe and a syringe pump (Model NE1000, New Era Pump Systems, Inc., Farmingdale, NY) was used to produce solid stents $1 \mathrm{~mm}$ in diameter by applying an air flow rate of $2.52 \mathrm{~L} / \mathrm{min}$ and a liquid flow rate of $0.5 \mathrm{~mL} / \mathrm{min}$. The setup preparation involved using a $20 \mathrm{G}$ needle for alginate material to flow coaxially while a sterile airflow moved vertically downward $[12,20]$, resulting in the extrusion of the hydrogel into a crosslinking solution of $1.5 \%$ or $10 \%$ $\mathrm{CaCl}_{2}$. The cross-linking time post-extrusion was set to $10 \mathrm{~min}$. The extent of cross-linking is adjusted by changing the $\mathrm{CaCl}_{2}$ concentration and the alginate concentration. This modulation in the membrane mesh size and thus pore size has been measured by differential scanning calorimetery [21]. Stents were then removed from the $\mathrm{CaCl}_{2}$ solution and rinsed twice with $0.9 \%(\mathrm{w} / \mathrm{v}) \mathrm{NaCl}$ and cut to a length of $100 \mathrm{~mm}$. The resulting solid stent is shown in Figure $1 \mathrm{~A}$.

\section{Hollow Fiber Preparation}

Hollow fibers were fabricated by a mold casting approach based on a previously published method [11], for which a metallic rod or wire of differing diameter sizes can be used as a basic mold. In this research, brass rods $1 \mathrm{~mm}$ in diameter were chosen. A thin layer of $2 \%$ medium viscosity alginate coats the rod and was submerged into a $10 \% \mathrm{CaCl}_{2}$ bath and set tor $1 \mathrm{hr}$ of cross-linking. The hollow fibers were gently removed from the rod and rinsed twice with $\mathrm{NaCl}$ and the resulting stent shown in Figure 1B. A coating layer approximately $4 \mu \mathrm{m}$ thick for the hollow fibers was an additional step. The hollow alginate microfibers were coated with $0.5 \%$ chitosan for an adsorption period of 45 min (for ACA synthesis) or with $0.1 \%$ polylysine for an adsorption period of 8 min (for APA synthesis).

Microfibers were subsequently coated with $0.1 \%$ $(\mathrm{w} / \mathrm{v})$ low viscosity alginate and submerged in $1.45 \%$ sodium citrate for 30 seconds. The amount of exposure time to sodium citrate determines the permeability of the synthesized stent, with long exposure times relating to increased permeability.

Fiber size measurement analysis was enabled by NIS-Elements v.3.2.2 software using a Nikon transmission microscope/camera (Nikon EclipseTiS/AndorTechnology Interline CCD camera). Microfibers used for diffusion studies were characterized by an outer diameter (od), of $\sim 1300 \mu \mathrm{m}$, inner diameter (id) $\sim 900 \mu \mathrm{m}$, a membrane thickness $(t) \sim 300 \mu \mathrm{m}$, and a 


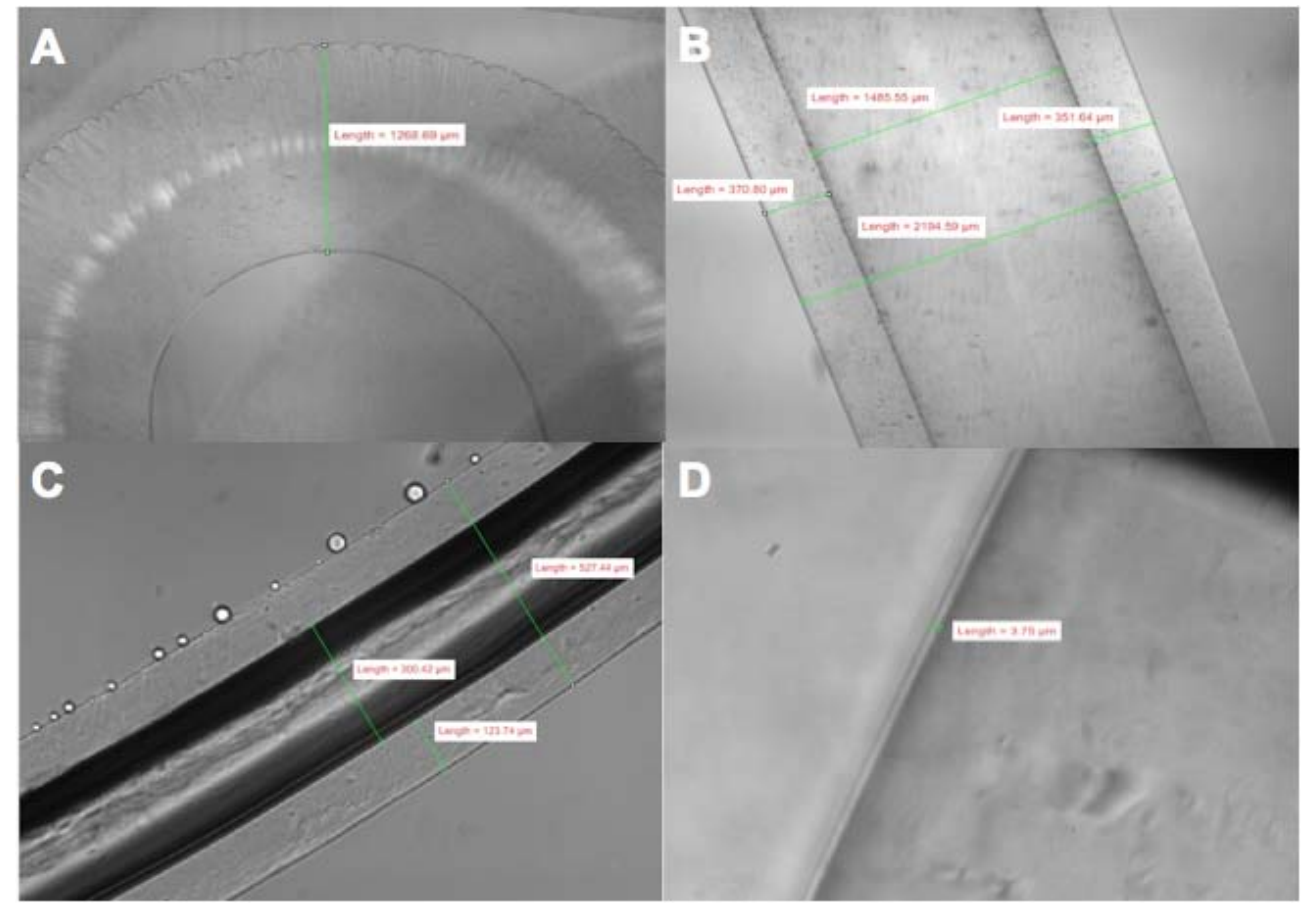

Figure 1: A) solid alginate stent configuration at 4X, B) hollow alginate stent fabricated with a $300 \mu \mathrm{m}$ diameter wire (od $\sim 500 \mu \mathrm{m}$, id $\sim 300 \mu \mathrm{m}, t \sim 100-150 \mu \mathrm{m}$, and $L=3.5 \mathrm{~cm}$ ), C) hollow alginate stent (od $\sim 1300 \mu \mathrm{m}$, id $\sim 900 \mu \mathrm{m}, t \sim 300 \mu \mathrm{m}$, and $L=3.5 \mathrm{~cm}$ ), D) alginate stent coated with $0.5 \%$ chitosan and $0.1 \%$ low viscosity alginate with a coating layer thickness of $t$ $\sim 3.75 \mu \mathrm{m}$.

length $(L)$ of $35 \mathrm{~mm}$ (Figure 1B). In addition, the smallest microfibers fabricated in our lab were done using a $300 \mu \mathrm{m}$ diameter wire with od $\sim 500 \mu \mathrm{m}$, id $\sim 300 \mu \mathrm{m}, t \sim 100-150 \mu \mathrm{m}$, and $L=35 \mathrm{~mm}$ (Figure 1C). The dimensions of the hollow fibers can be tailored to specific applications. The average thickness of the chitosan-alginate coating layer was $3.75 \mu \mathrm{m}$ (Figure 1D).

A basic diagram of a hollow alginate microfiber is given in Figure 2A along with an actual hollow microfiber after fabrication (Figure 2B). The terms $r_{1}$ and $r_{2}$ correspond to the inner and outer radii of the hollow structure, used as boundary conditions throughout this article.

\section{Basis for Theoretical Diffusion Model}

Characterization of the diffusion behavior of solutes through a polymer membrane can be achieved by implementing a mathematical model based on Fick's laws of diffusion. Previously, solute diffusion through alginate based microspheres coated with polylysine (PLL) or chitosan has been modeled with networks of different molecular weights $[14,22,23]$. The spherical diffusion equations (Eqns. 1 and 2), derived from the hollow sphere model given by Carslaw and Jaeger [24],
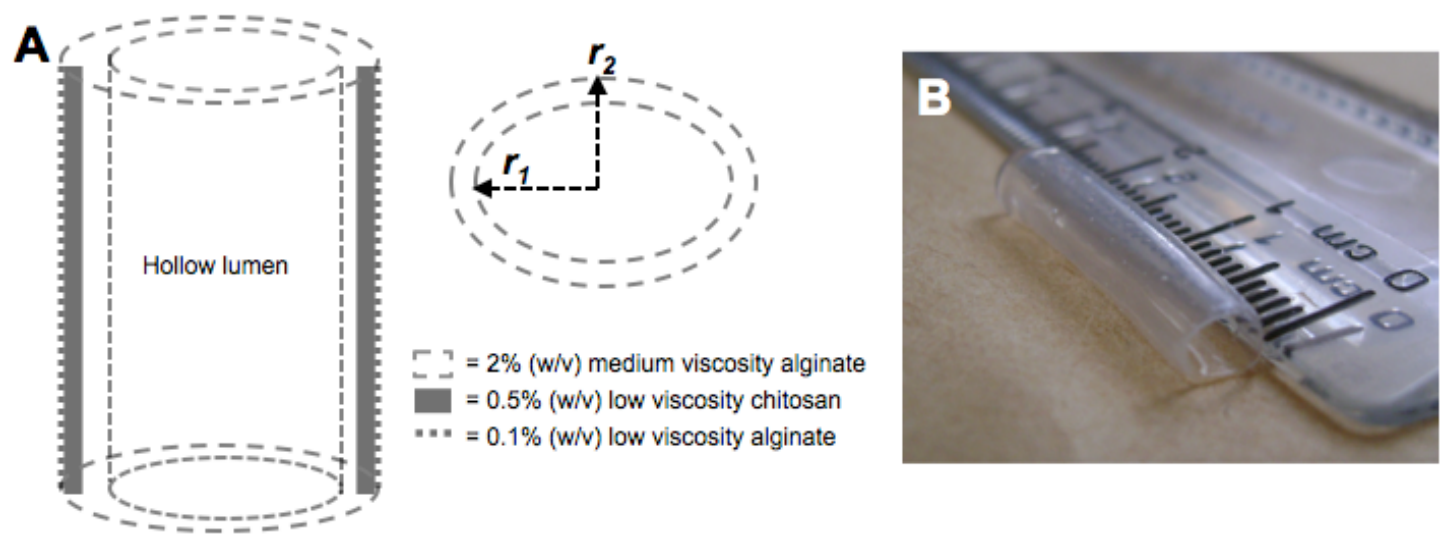

Figure 2: A) diagram of hollow microfiber with axial and cross-sectional views, B) hollow alginate stent after fabrication with a $1 \mathrm{~mm}$ brass rod. 
describe the diffusion characteristics in membranes. Eqn. 1 describes the concentration gradient of different substrates, which is also a form of Fick's first law [25],

$-\frac{d C_{b}}{d t}=\frac{3}{r_{2}} \frac{V_{2}}{V_{b}} D\left(\frac{\partial C_{m}}{\partial r}\right)_{r_{2}}$

and Eqn. 2 represents Fick's second law with given initial condition and boundary conditions for the spherical model case (Eqns. 3-5). All equation parameters are defined in the Appendix. Methods for finding a solution to this set of equations were based on numerical approaches used by Carnahan [26] and Crank [27].

$\frac{\partial C_{m}}{\partial t}=\frac{1}{r^{2}} \frac{\partial}{\partial r}\left(D r^{2} \frac{\partial C m}{\partial r}\right)$

I.C.: $t=0, C_{m}(r, 0)=C_{m 0}$

B.C. $1: r=r_{2}, C_{m}=C_{e q}$

B.C. $2: r=r_{1}, \frac{\partial C_{m}}{\partial r}=0$

In Eqn. 1, the flux represents the amount of solute that flows through a unit area per unit time and relates to the solute concentration gradient at the interface between the membrane and bulk solution. In Eqn. 2, the term $\left(\mathrm{dC}_{\mathrm{m}} / \mathrm{dt}\right)$ represents the rate of change in solute concentration in the membrane, $D$ is solute diffusivity through the membrane, $r$ is the radial position, and $\left(\mathrm{dC}_{\mathrm{m}} / \mathrm{dr}\right)$ is the solute concentration gradient in the membrane. As a result of solute diffusion into the membrane, the intracapsular solute concentration increases. This method assumes the size and shape of diffusing solutes are dominant factors determining membrane permeability and that there is a negligible diffusive effect due to electrostatic forces [28]. If Eqns. 1 and 2 are numerically solved in MATLAB (R2010a) using the initial condition and two boundary conditions in Eqns. 3-5, the diffusion coefficient can be determined by trial and error. Although these equations form a mathematical basis for determining diffusive behavior of membranes, this trial and error approach assumes a $D$ value since it cannot be solved directly. A theoretical cylindrical model has been developed to address the potential inaccuracies of the trial and error method.

\section{Modified Numerical Model Based on Diffusion equations in Cylindrical Coordinates}

The new modified model proposed in this study is a standard numerical solution for a system of parabolic partial differential equations, such as the diffusion equations. The exact solutions given, which closely approximate diffusivity, are stable and known to converge within the range of numerical accuracy. The cylindrical form of the diffusion equations (Eqns. 1 and 2) has been used to model and analyze solute diffusion through prepared alginate based micro-cylinders. Eqn. 6 represents the one-dimensional Fick's second law of diffusion in cylindrical coordinates. The equation considers only the radial dimension, since diffusion is dominant to occur in the radial direction:

$\frac{\partial C_{m}}{\partial t}=\frac{1}{r} \frac{\partial}{\partial r}\left(D r \frac{\partial C_{m}}{\partial r}\right)$

The boundary conditions and initial condition are shown in Eqns. (7)-(9), proposed initially by Flynn [22] and Kwok [13]. In Eqn. 9, solute concentration gradient behavior at the alginate membrane is expressed by a form of Fick's first law, and this set of equations (Eqns. 7-9) applies to known experimental conditions [13, 22, 24]. In the case of inward diffusivity, micro-cylinders with a semi-permeable membrane are put in suspension with solutions of varying molecular weight solutes.

I.C $: \mathrm{C}_{\mathrm{m}}(\mathrm{r}, 0)=0$

B.C. $1: \frac{\partial \mathrm{C}_{\mathrm{m}}}{\partial \mathrm{r}}=0$ at $\mathrm{r}=\mathrm{r}_{1}$

$\mathrm{BC} 2:-\frac{\mathrm{dC}_{\mathrm{b}}}{\mathrm{dt}}=\frac{\mathrm{A}_{2}}{\mathrm{~V}_{\mathrm{b}}} \mathrm{D} \frac{\partial \mathrm{C}_{\mathrm{m}}}{\partial \mathrm{r}}$ at $\mathrm{r}=\mathrm{r}_{2}$

The following assumptions are used:

1. The bulk concentration of the solution is uniform.

2. Diffusion is most rapid through the semipermeable membrane.

3. In the case of a solid cylinder, the core is impermeable. Beyond threshold thickness, diffusion is negligible.

4. Bulk volume held constant, microfibers all have the same dimensions and hold the same amount of solute at any given time.

By solving the partial differential equation (Eqn. 6), the value of diffusivity, $D$, is still not directly calculable. A standard approach of non-dimensionalizing this set of equations (Eqns. 6-9) has been applied. In our experiments, the physical quantities to be non- 
dimensionalized are $t, C$, and $r$, and are defined as shown in Eqns. 10-13,

$\tau \equiv \frac{D t}{\left(r_{2}-r_{1}\right)^{2}}$

$\xi \equiv \frac{C_{m}-C_{0}}{C_{b 0}-C_{0}}$

$\xi_{b} \equiv \frac{C_{b}-C_{0}}{C_{b 0}-C_{0}}$

$\chi \equiv \frac{r}{r_{2}-r_{1}}$

where $\tau, \xi, \xi_{\mathrm{b}}$, and $\chi$ are non-dimensionalized time, membrane concentration, bulk concentration, and radius, respectively. By differentiating Eqn. 11 with respect to $t$ and $r$ and substituting these terms back into the original PDE (Eqn. 6), the following equation results:

$\frac{\partial \xi}{\partial t}=\frac{1}{r} \frac{\partial}{\partial r}\left(\operatorname{Dr} \frac{\partial \xi}{\partial r}\right)$

In order to remove the variables $t$ and $r$ from Eqn. 14 , a change of variables gives:

$\frac{\partial \xi}{\partial \tau}=\frac{1}{r} \frac{\partial}{\partial \chi}\left(r \frac{\partial \xi}{\partial \chi}\right)=\frac{1}{\chi\left(r_{2}-r_{1}\right)} \frac{\partial}{\partial \chi}\left[\chi\left(r_{2}-r_{1}\right) \frac{\partial \xi}{\partial \chi}\right]$

The final reduced form of the non-dimensionalized PDE is given by:

$\frac{\partial \xi}{\partial \tau}=\frac{1}{\chi} \frac{\partial}{\partial \chi}\left(\chi \frac{\partial \xi}{\partial \chi}\right)$

Similarly, the initial condition and boundary conditions must also be non-dimensionalized. The original boundary condition (Eqn. 9),

$-\frac{d c_{b}}{d t}=\frac{A_{2}}{V_{b}} D \frac{\partial C_{m}}{\partial r}$ B.C. at $r=r_{2}$

is converted into the following form,

$-\frac{d \xi_{b}}{d t}=\frac{A_{2}}{V_{b}} D \frac{\partial \xi}{\partial r}=\frac{2}{r_{2}} \frac{V_{2}}{V_{b}} D \frac{\partial \xi}{\partial r}$

where $A_{2}$ is the surface area of a stent $\left(A_{2}=2 \pi R_{2} h\right)$ and $V_{b}$ is the bulk volume, and $V_{2}$ is the stent volume $\left(V_{2}=\pi R_{2}^{2} h\right)$. After applying a change of variables, the final non-dimensionalized form of Eqn. 9 is determined: $-\frac{d \xi_{b}}{d t}=2 \frac{V_{2}}{V_{b}}\left(1-\frac{r_{1}}{r_{2}}\right) \frac{\partial \xi}{\partial \chi}$ at $\chi_{2}=\frac{r_{2}}{r_{2}-r_{1}}$

Equations 6-19 form a basis for a mathematical model which can be implemented into modeling software such as MATLAB (R2010a) for numerical solving. An experimental example of diffusion through a hollow microfiber using this model is given in the Results section.

\section{Analytical Solution for Cylindrical Diffusion Equation}

The analytical solution for the cylindrical diffusion equation (Eqn. 2) is derived in this section, where the initial condition and boundary conditions are given by Eqns. 3-5. The solution considers a solid cylinder and is found by separation of variables like the approach discussed by Carslaw and Jaeger (1969). Eqn. 2 is rewritten in the form:

$\frac{1}{D} \frac{\partial C_{m}}{\partial t}=\frac{\partial^{2} C_{m}}{\partial r^{2}}+\frac{1}{r} \frac{\partial C_{m}}{\partial r}$

Following separation of variables using the substitution $\mathrm{C}_{\mathrm{m}}(r, t)=\mathrm{R}(\mathrm{r}) \mathrm{T}(\mathrm{t})$, the equation becomes:

$\frac{1}{D} \frac{1}{T} \frac{d T}{d t}=\frac{1}{R} \frac{d^{2} R}{\partial r^{2}}+\frac{1}{r R} \frac{\partial R}{\partial r}=-k^{2}$

The solution for $T(t)$ is of the form: $T(t)=C \exp \left(-k^{2} D t\right)$, where $C$ and $k$ are constants. The separation of $r$ terms in Eqn. 21 gives a Bessel differential equation of order zero:

$\frac{d^{2} R}{d r^{2}}+\frac{1}{r} \frac{d R}{d r}+k^{2} R=0$

The general solution to Eqn. 22 becomes,

$C_{m}(r, t)=C_{e q}+\sum_{n=1}^{\infty} A_{\mathrm{n}} J_{0}\left(\frac{x_{n}}{r_{2}}\right) e^{\left(\frac{-x_{n^{2}}}{r^{2}} D t\right)}$

where $k_{n} r_{2}=x_{n}$ are the zeros of the Bessel function $J_{0}(x)$ and have been calculated using the boundary conditions as:

$x_{1}=2.404, x_{2}=5.52, x_{3}=8.65, x_{4}=11.79\left(k_{1}, k_{2}, k_{3}, \ldots, k_{n}\right.$ are known)

Based on orthogonality conditions and application of the initial condition, the constant $A_{n}$ has been determined to be: 


$$
A_{n}=\frac{2\left(C_{0}-C_{e q}\right) \int_{0}^{r_{2}} J_{0}\left(\frac{x_{n}}{r_{2}} r\right) r d r}{r^{2}{ }_{2}\left[J_{1}\left(x_{n}\right)\right]^{2}}
$$

which reduces to the form:

$$
A_{n}=\frac{2\left(C_{0}-C_{e q}\right)}{x_{n} J_{1}\left(x_{n}\right)}
$$

The final form of Eqn. 23 then becomes:

$C_{m}(r, t)=C_{e q}+2\left(C_{0}-C_{e q}\right) \sum_{n=1}^{\infty} \frac{J_{0}\left(\frac{x_{n}}{r_{2}} r\right) e\left(\frac{-x_{n}^{2}}{r^{2}} D t\right)}{x_{n} J_{1}\left(x_{n}\right)}$

The form of the analytical solution in Eqn. 27 can also be non-dimensionalized in order to be compared with the modified mathematical model in the previous section. This implementation leads to converting Eqns. 20-22 to non-dimensionalized forms based on the definitions given by Eqns. 10-13. The solution for $T(t)$ becomes $T(\tau)=\exp (-\lambda \tau)$, and $R(r)$ becomes $X(X)$ and Eqn. 22 is rewritten as:

$\frac{d^{2} X}{d \chi^{2}}+\frac{1}{\chi} \frac{d X}{d \chi}+k^{2} X=0$

where $\mathrm{k}^{2} \equiv \lambda$, and the roots of the dimensionless Bessel differential equation (Eqn. 28) are: $X_{n}(X)=J_{0}\left(k_{n} X\right)$. The boundary conditions and initial condition (Eqns. 3-5) become:

$$
\begin{aligned}
& \text { I.C. }: \xi(\chi, 0)=0 \\
& \text { B.C. } 1: \frac{d \xi}{d \chi}=0 \text { at } \chi=0
\end{aligned}
$$

B.C. $2: \xi\left(r_{2}, \tau\right)=1$

Using Eqns. 29-31, the general solution of Eqn. 23 is transformed as:

$$
\xi(\chi, \tau)=\xi_{1}+\sum_{n=1}^{\infty} A_{n} J_{0}\left(k_{n} \chi\right) e^{\left(-k_{n} \tau\right)}
$$

thus the final form of the non-dimensionalized analytical solution becomes:

$\xi(\chi, \tau)=1-2 \sum_{n=1}^{\infty} \frac{J_{0}\left(\frac{x_{n} \chi}{\chi^{2}}\right) e^{\left(\frac{-x_{n^{2}}}{\chi^{2^{2}} \tau}\right)}}{x_{n} J_{1}\left(x_{n}\right)}$

where $\chi_{2}=r_{2} /\left(r_{2}-r_{1}\right), \chi$ is given by Eqn. $13, \tau$ is given by Eqn. 10, and $x_{n}$ 's are given by Eqn. 24. This analytical or theoretical solution can be used to validate our numerical solution using experimental diffusion data from a solid stent.

\section{Validation of Mathematical Model}

A validation approach for the modified diffusion model derived in this study is to compare its results against a purely theoretical (analytical) model. The analytical model, as previously discussed, employs

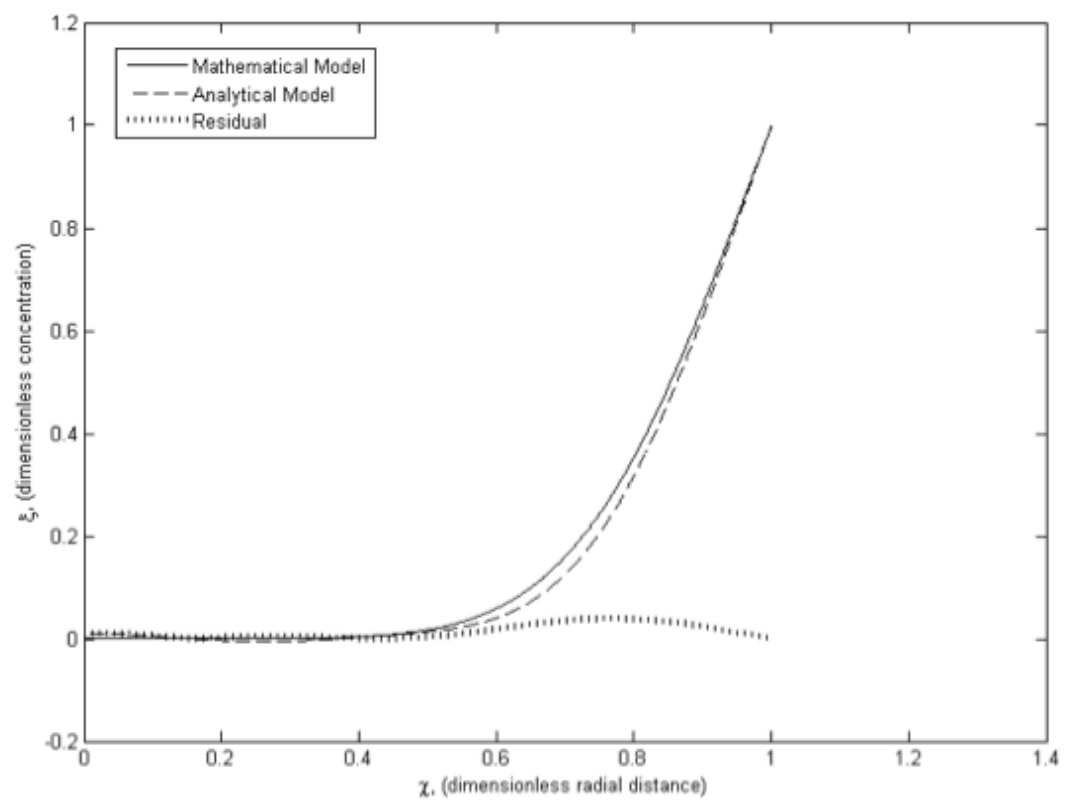

Figure 3: Validation of the cylindrical 1D Fickian numerical model for creatinine diffusion through solid microfibers by superimposition of diffusivity profiles simulated by the numerical and analutical models. 
simplified boundary conditions (Eqns. 4-5) as compared to the more complex yet more physically realistic boundary conditions (Eqns. 8-9). The correlative capacity in the two models rests on the assumption that diffusion is occurring inwardly through a solid cylinder, and that the diffusion equations are non-dimensionalized and analyze a specific region within the cylinder. For the purposes of validation, diffusion of creatinine through a solid cylinder from the outer radius to the inner radius was investigated. The diffusion coefficient determined based on experimental data using the modified mathematical model was input into the analytical solution. A dimensionless creatinine diffusion profile within the alginate micro-cylinder generation by both models is given by Figure 3 . The Matlab codes for both models were combined into a single code. The residual values (i.e. the point-by-point algebraic difference) between the mathematical and analytical models are highlighted more clearly in Figure 4. The maximum percentage of error was found to be $4 \%$ between the models.

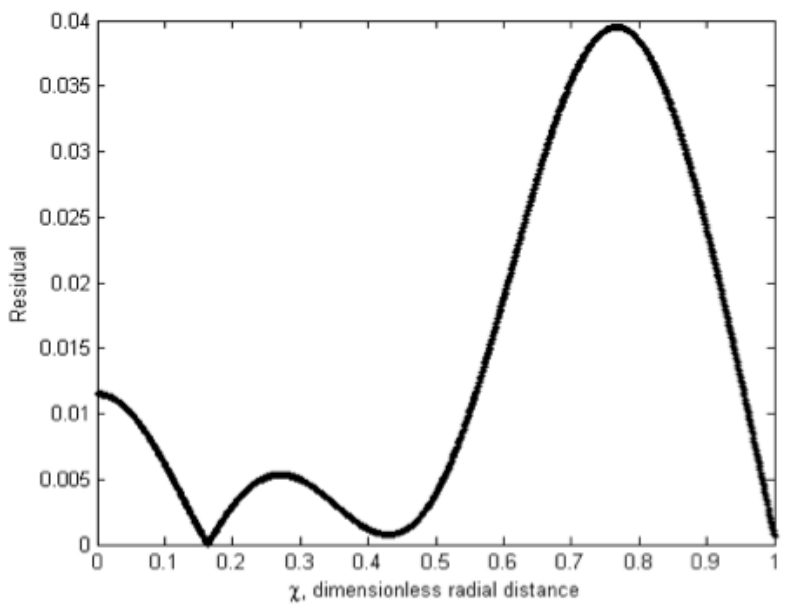

Figure 4: Residuals calculated between the mathematical and analytical models.

\section{RESULTS}

\section{Diffusion Experiments Across Alginate Microfibers by Spectrophotometry}

Based on the validation approach of the modified mathematical model using solid micro-cylinder data, the model can be accurately applied to concentration profiles across hollow fibers. An inward diffusion study involving uptake of solutes into empty alginate microfibers coated with $0.5 \%$ chitosan or $0.1 \%$ PLL was performed. The chosen solutes, creatinine, PEG and albumin have a wide molecular weight range spanning from 110-68,000 Da. Creatinine was chosen to simulate the diffusive behavior of low MW drugs namely salicylic acid and diclofenac previously entrapped in alginate microfibers [28, 30]. PEG-6000 was chosen as the model middle MW molecule simulating the behavior of toxins during hemoperfusion, a treatment for which the use of alginate fibers instead of the use of cellulose nitrate and polyamide has been explored [31]. Albumin was chosen as model high MW solute reported to be at the molecular weight cutoff of cross-linked alginate membrane in spherical configuration $[14,23]$. The physical properties of these solutes are given in Table 1. For diffusion experiments, empty microfibers were suspended in a volume of 15 $\mathrm{mL}$ creatinine, and $200 \mu \mathrm{L}$ of the supernatant was sampled every $15 \mathrm{~s}$ for the first minute, every $30 \mathrm{~s}$ for the next $3 \mathrm{~min}$, and every $60 \mathrm{~s}$ for the remaining $5 \mathrm{~min}$. Sampling stopped when the equilibrium concentration $\left(\mathrm{C}_{\text {eq }}\right)$ was reached and no more concentration changes were detected $(\mathrm{dC} / \mathrm{dt}=0)$. All $200 \mu \mathrm{L}$ samples from each run were taken to the UV-Vis spectrophotometer for measuring peak absorbance values of creatinine, PEG3500 , PEG-6000, and albumin at wavelengths $\lambda=265$ $\mathrm{nm}, 285 \mathrm{~nm}, 280 \mathrm{~nm}$, and $280 \mathrm{~nm}$, respectively. A calibration equation was used to convert absorbance measurements into concentration, and a trend of the concentration profile for each solute at the membrane surface is plotted.

Experimental measurements attained from spectrophotometry runs give absorbance values over different time points, which are normalized to the absorbance at time zero. A sample creatinine concentration curve is shown in Figure 5. The initial concentration and equilibrium concentration are also determined from the curve; $C_{i}$ represents the first measurement at time, $t=0 \mathrm{~s}$, and $\mathrm{C}_{e q}$ is a mean value of the last 3-4 measurements when the concentration stabilizes toward a minimum value.

Table 1: Diffusing Solutes and their Physical Properties $[12,14]$

\begin{tabular}{|c|c|c|c|}
\hline & Creatinine & PEG & Albumin \\
\hline \hline Molecular Weight $(\mathrm{Da})$ & 113 & 6000 & 68,000 \\
\hline Stkes radius $(\mathrm{nm})$ & 0.36 & 1.34 & 2.99 \\
\hline UV-VIS absorbance range $(\mathrm{nm})$ & $240-270$ & $220-290$ & $230-280$ \\
\hline
\end{tabular}




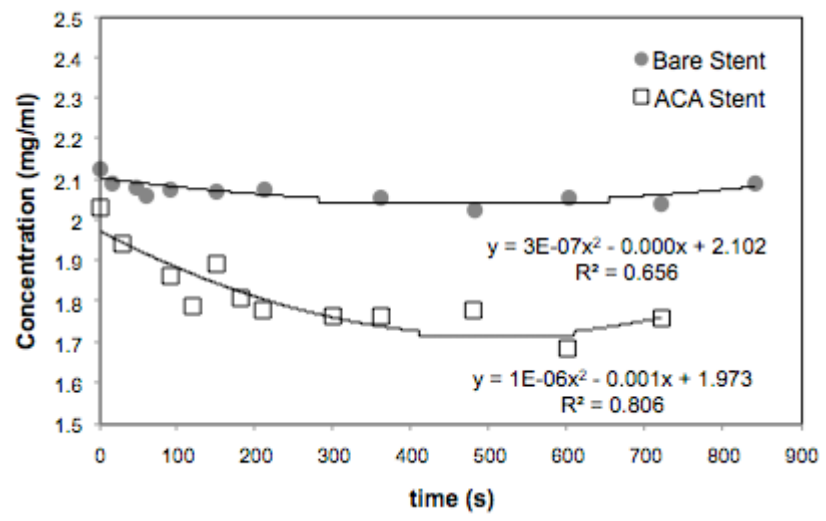

Figure 5: Sample creatinine diffusion profile of empty hollow stent (bare) and alginate-chitosan-alginate hollow stent (ACA).

\section{Diffusivity Computation Using the Modified Numerical Mathematical Model}

Further explanation is given in this section to the calculation of diffusivity using the mathematical model implemented in MATLAB. Experimental measurements attained from spectrophotometry runs give absorbance values over different time points, which are normalized to the absorbance at time, $\mathrm{t}=0$. Shown in Figure $\mathbf{5}$ are examples of bulk creatinine concentration profiles obtained from spectrophotometric measurements using solute-specific a calibration curve. The initial concentration and equilibrium concentration are also determined from the curve; $\mathrm{C}_{i}$ represents the first measurement at time, $t=0$, and $\mathrm{C}_{\text {eq }}$ is a mean value of the last 3-4 measurements when the concentration stabilizes toward a minimum value.

The bulk concentration profile $\left(C_{B}\right)$ in Figure 5 has been correlated to a second order polynomial $\left(R^{2}=0.6564\right.$ for bare stents, $R^{2}=0.8061$ for ACA stents). The following steps (Table 2) are to be conducted before and after inputting equations into MATLAB. After all variables and expressions were implemented into MATLAB (see Appendix A), the resulting graph generated a non-dimensionalized concentration versus non-dimensionalized radial distance profile, or a $\xi$ vs. $\chi$ curve. The $x$-axis is determined by plugging in known experimental bulk concentration values and other physical variables of the system into Eqn. 9. The final step is to assume a $D$ value as an input into the pde solver, and the diffusion profile will either overshoot ( $\xi$ $>1$ ) or undershoot $(\xi<1)$. The correct approximation of diffusivity, D, will occur when $\xi=1$. Sample dimensionless diffusion profiles obtained as a result of the trial and error procedure described above are illustrated in Figure 6 . The convergence of diffusion coefficients is sought by obtaining stable numerical solutions of the diffusion partial differential equations (PDE) subject to the satisfaction of initial and boundary conditions as previously discussed. From the theory of linear PDE's and pertinent numerical solutions, a unique solution is achieved once stable numerical solutions are obtained. The stability of the numerical solution is subject to an appropriate range of the diffusion coefficients and proper partitioning of space and time domains, i.e. space and time mesh sizes $X$ and $\tau$. A number of trial and error runs were made to determine the appropriate range of such parameters. To attain an appropriate range of $D$, values first resulted as unbounded, unstable solutions but several runs of numerical solutions narrowed the range of an acceptable D. Next the space and time mesh sizes (domain partitioning) were changed to determine the stable non-oscillatory solutions. According to the theory of numerical solutions, inappropriate partitioning results in oscillatory solutions. Accurate and stable solutions are achieved when further domain partitioning makes no changes in the solutions. In this model, the diffusion coefficient stability range was analyzed from $n=100$ to $n=1000$ partitions. Between $n=100$ to $n=200$, the variance in the solved diffusion coefficients was approximately $30 \%$, however between $n=900$ and $n=1000$ this variance was $<5 \%$ which is an acceptable range. Due to the accuracy of the solution being attained for partitioning above $n=900$, we chose to

Table 2: Summary of Steps to Perform to Integrate Mathematical Model into MATLAB

\begin{tabular}{|c|c|}
\hline Before Inputting to Matlab & Actions to do in Matlab \\
\hline \hline 1. Find $\xi_{b}(\mathrm{t})$ by inputting equation for $C_{b}(\mathrm{t})$ & $\begin{array}{c}\text { 1. Define variables (including dimensionless variables): } \\
R_{1}, R_{2}, C_{b 0}, C_{0}, D, V_{2}, \tau, \chi_{1}, \chi_{2}\end{array}$ \\
\hline 2. Find $\mathrm{d} \xi_{b} / \mathrm{dt}$ & 2. In pdex1pde file: $c=1, f=D c D r$, and $s=0$ \\
\hline 3. Convet $t \rightarrow \tau$ by inputting definition of $t$ (Eqn. 10), left with $\mathrm{d} \xi_{b} / \mathrm{d} \tau$ & 3. In pdex1ic file: $c_{0}=0$ \\
\hline 4. Determine I.C. and B.C.'s & $\begin{array}{c}\text { 4. In pdex1bc file: } \\
\mathrm{p}_{\mathrm{l}}=0, \mathrm{q}_{\mathrm{l}}=1\end{array}$ \\
& $\mathrm{p}_{\mathrm{r}}=\mathrm{d} \xi_{b} / \mathrm{dt}$ (use Eqn. 12), $\mathrm{q}_{\mathrm{r}}=\mathrm{Eqn}$. 19 \\
\hline
\end{tabular}




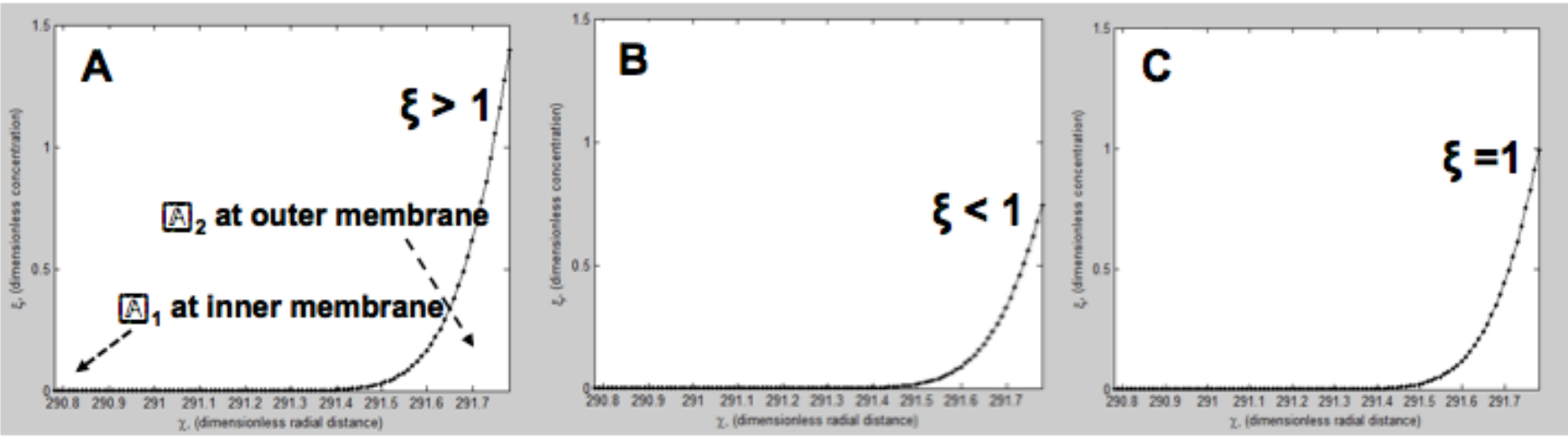

Figure 6: Sample dimensionless diffusion profile when A) $D$ has been overestimated and B) $D$ has been underestimated, C) when $\mathrm{D}$ has been accurately approximated.

solve for all diffusion coefficients at $n=1000$ partitions. A sample curve (Figure 7 ) is given to show the convergence of $\mathrm{D}$ values with increased partition values.

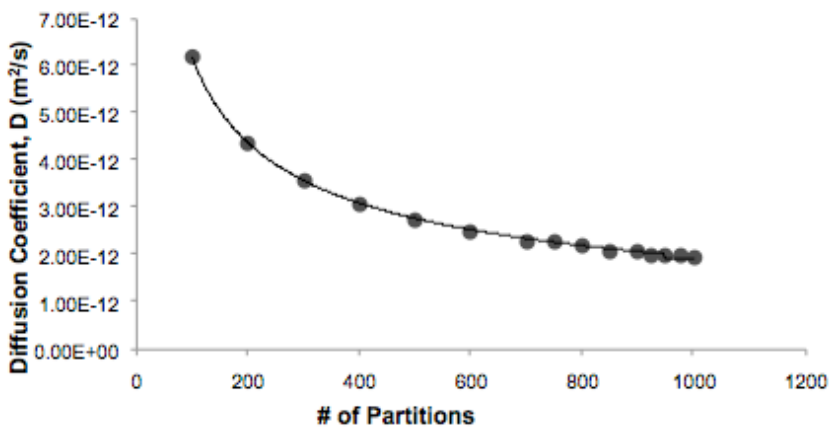

Figure 7: Sample curve of diffusion coefficients (D) at different partition values depicting creatinine diffusion into an ACA hollow stent.

This method of numerically solving for the diffusivity, $D$, has been used to find $D$ for different alginate membranes and for solutes with a wide range of molecular weights, as explained in the following section. This approach can also be applied to any diffusion study that follows a similar experimental protocol as described in this study.

\section{Diffusivities for Solutes with a Molecular Weight Range: $110<M W<68,000 \mathrm{Da}$}

The modified mathematical model was used to numerically solve for the diffusivity, $D$, of various solutes (i.e., creatinine, PEG and albumin) with a range in molecular weight from $110<\mathrm{MW}<68,000 \mathrm{Da}$. The alginate microfiber membrane types under investigation for this study were: uncoated (bare), alginate-chitosanalginate (ACA), and alginate-PLL-alginate (APA). Diffusion profiles $\left(A / A_{0}\right.$ vs. time) were generated for solid ACA microfibers with all diffusing solutes (Figure 8A) and for albumin through hollow uncoated and ACA membranes (Figure 8B). Diffusion profiles of uncoated, ACA and APA membranes of hollow fibers were also attained for creatinine (Figure 9A) and PEG (Figure 9B). For each membrane and solute type, diffusion experiments were triplicated. Experimental results and statistical analysis of the empirical diffusivity data are presented in Figure $\mathbf{1 0}$ and Table 3. For all membrane types, the diffusivity of albumin is an order of magnitude smaller than the coefficients computed for the other two solutes. Restricting the comparison to creatinine $(\mathrm{a}=0.36 \mathrm{~nm})$ and PEG $6000(\mathrm{a}=1.34 \mathrm{~nm})$, in average, solute diffusivity through the bare $\left(1.02 \times 10^{-12}\right.$.
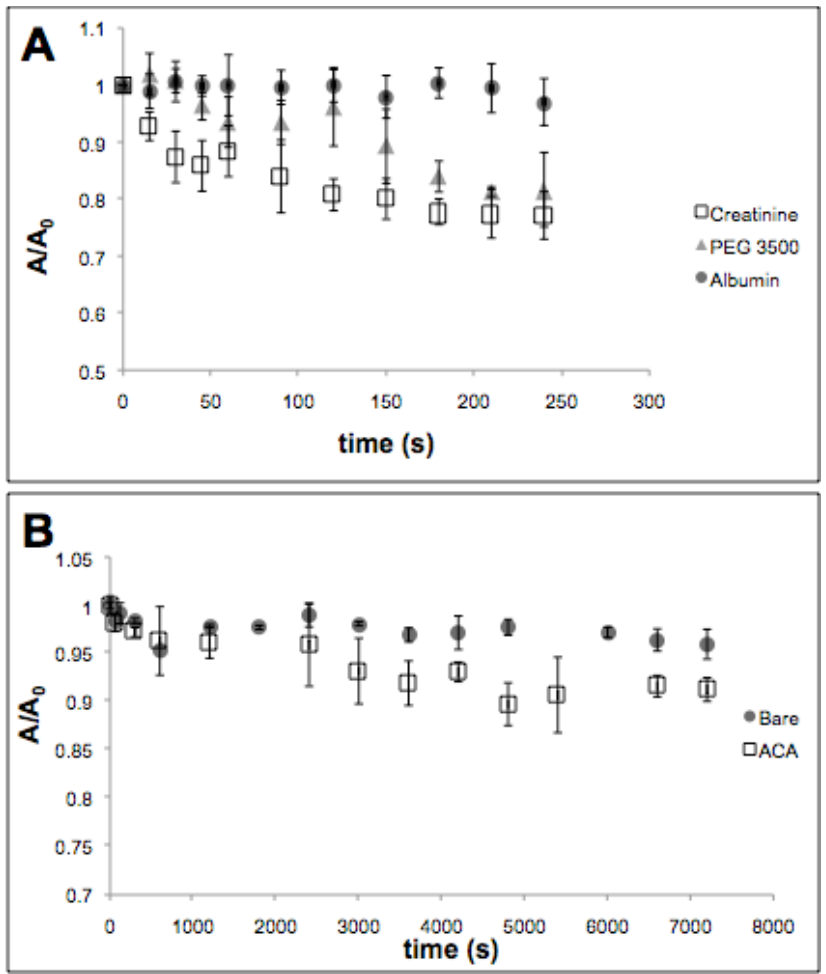

Figure 8: A) diffusion profile of solid ACA microfibers for creatinine, PEG-6000, and albumin (N=3), B) diffusion profile of albumin for hollow uncoated (bare) and ACA microfibers treated with $90 \mathrm{~s}$ sodium citrate $(\mathrm{N}=3)$. 


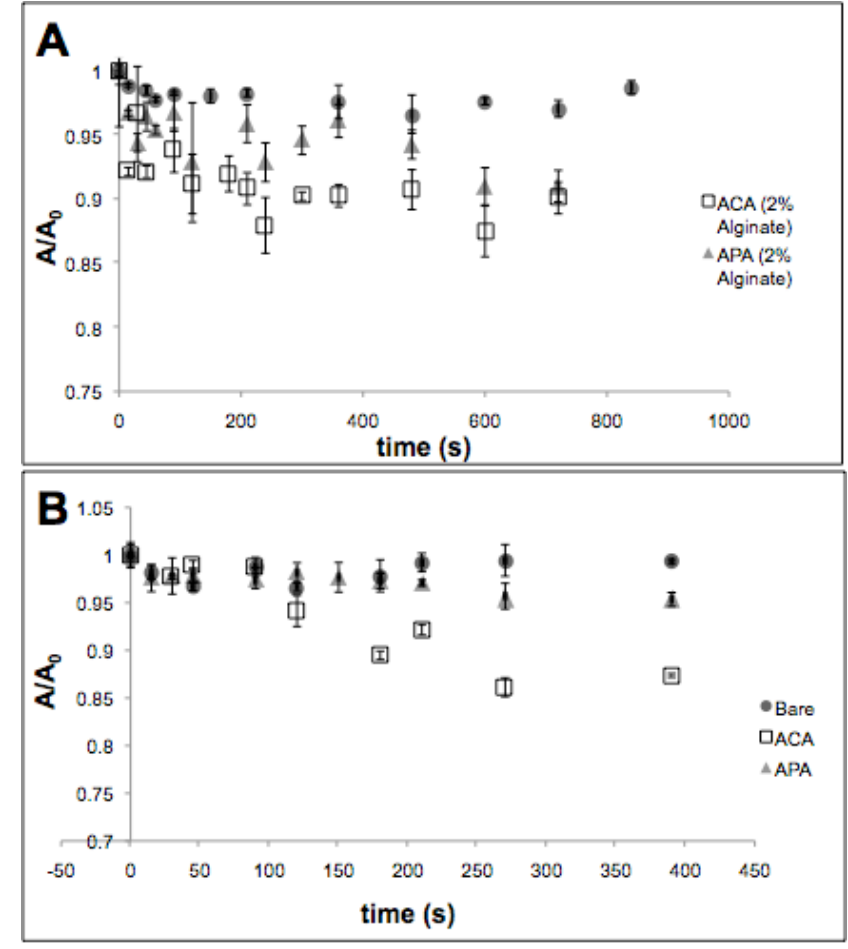

Figure 9: A) comparison of creatinine diffusion profiles of uncoated (bare), ACA, and APA membranes for hollow microfibers treated with $30 \mathrm{~s}$ sodium citrate $(\mathrm{N}=3)$, B) comparison of PEG-6000 diffusion profiles of uncoated, ACA, and APA membranes for hollow stents treated with $30 \mathrm{~s}$ sodium citrate $(\mathrm{N}=3)$.

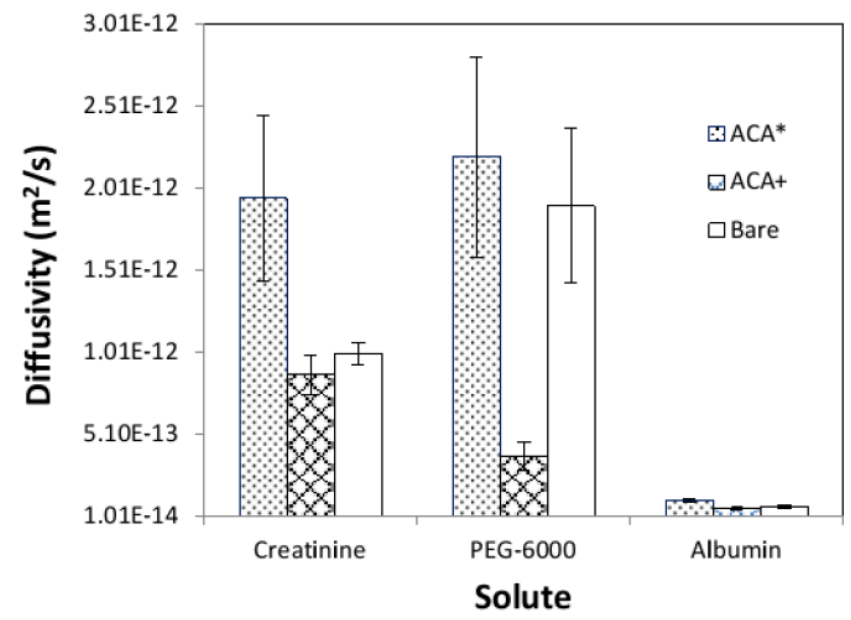

Figure 10: Comparison of solute diffusivity across alginate membranes.

$\left.1.9 \times 10^{-12} \mathrm{~m}^{2} / \mathrm{s}\right)$ and ACA $\left(1.95 \times 10^{-12}-2.20 \times 10^{-12} \mathrm{~m}^{2} / \mathrm{s}\right)$ hollow microfibers is an order of magnitude higher than the solid microfiber configuration $\left(3.70 \times 10^{-13}-8.07 \mathrm{x}\right.$ $\left.10^{-13} \mathrm{~m}^{2} / \mathrm{s}\right)$. For these aforementioned $2 \%(\mathrm{w} / \mathrm{v})$ alginate membranes, computed diffusivity values for the two solutes had the same order of magnitude. For the $3 \%(\mathrm{w} / \mathrm{v})$, creatinine diffusivity was approximately four times higher for the APA as compared to the ACA membrane. With a coefficient of variation $(\mathrm{CV})$ of $35 \%$ for the APA membranes and a sample size of 3 , inadequate for statistical significance testing the difference in diffusivity results between the ACA and APA membranes could be interpreted as experimental noise.

\section{DISCUSSION}

The closest computed diffusivity values to those of the cylindrical microfibers obtained through the use of Fickian modeling are published values for diffusion coefficients across spherical microcapsule membranes also measured spectrophotometrically [12-14]. Bare and ACA microcapsule membranes are slightly permeable to albumin, a finding confirmed by fluorescence microscopy using the $70 \mathrm{kDa}$ FITCdextran marker [32] and additionally confirmed in this study for microfibers. As for the interpretation of the slower diffusion through the solid ACA fiber as compared to the hollow microfibers, it could be inferred that the solutes freely diffuse through the empty lumen of the hollow fiber, while the core of the solid cylinder is populated by cross-links through which molecules should diffuse. From the proximity of the diffusivity values for PEG-6000 and creatinine given a Stokes radius ratio of $3: 7: 1$, it could be hypothesized that the membrane pore size far exceeds the molecular size. The cross-linked membrane pore size measured by atomic force microscopy was reported to be $6 \mathrm{~nm}$ for a $2 \%(\mathrm{w} / \mathrm{v})$ alginate film ${ }^{1}$, rendering the PEG-6000 and creatinine membrane to pore size ratio 4.6 and 16.7 , respectively. Thus, the above hypothesis is validated. Albumin is negatively charged at $\mathrm{pH}=7.4$ and so is alginate. In case of albumin, transport across the membrane is hindered by electrostatic repulsion and slowed down as compared to the other two solutes with a membrane to pore size ratio of 2 . As previously reported, alginate-based macro (hundreds of micron range) and microscale (micron range) fibers fabricated using extrusion, mold casting and microfluidic-based technologies have been used in a variety of drug delivery and tissue engineering applications [33]. The following are representative cases of quantified release studies from cylindrical alginate fibers with unreported diffusivity values. Release of salicylic acid $(a=0.38$ $\mathrm{nm})$ [29] and diclofenac $(\mathrm{a}=0.49 \mathrm{~nm})$ [30] has been measured. Permeability of alginate microfibers

${ }^{1}$ Simpliciano C, Asi B. Pore size determination and validation using AFM and spectrophotometry: 2012: Proceedings of the Third Bay Area Biomedica Devices Conference, San Jose, CA, [online] Available for free access a http://www.engr.sjsu.edu/ bmes/BMDConf2012/abstract4.html for free access. 
Table 3: Statistical Analysis of Membrane Diffusivities of Different Microfiber Membranes as a Function of Solute Type

\begin{tabular}{|c|c|c|c|c|}
\hline Membrane & Diffusing Solute & Average Diffusivity, $D\left(\mathrm{~m}^{2} / \mathrm{s}\right)$ & Std. Deviation, of $D\left(\mathrm{~m}^{2} / \mathrm{s}\right)$ & $c V \%$ \\
\hline $\mathrm{ACA}^{*}$ & Creatinine & $1.95 \mathrm{E}-12$ & $5.05 E-13$ & 25.9 \\
\hline $\mathrm{ACA}^{*}$ & PEG-6000 & $2.20 \mathrm{E}-12$ & $6.12 \mathrm{E}-13$ & 27.8 \\
\hline $\mathrm{ACA}^{*}$ & Albumin & $1.02 \mathrm{E}-13$ & $8.74 \mathrm{E}-15$ & 8.60 \\
\hline $\mathrm{ACA} \dagger$ & Creatinine & $8.70 \mathrm{E}-13$ & $1.17 \mathrm{E}-13$ & 13.4 \\
\hline $\mathrm{ACA} \dagger$ & PEG-6000 & $3.70 \mathrm{E}-13$ & 8.77E-14 & 23.7 \\
\hline $\mathrm{ACA} \dagger$ & Albumin & $5.20 \mathrm{E}-14$ & $7.95 \mathrm{E}-15$ & 15.3 \\
\hline $\mathrm{ACA}^{* *}$ & Creatinine & $7.85 \mathrm{E}-13$ & $9.51 \mathrm{E}-14$ & 12.1 \\
\hline $\mathrm{APA}^{* *}$ & Creatinine & $2.93 \mathrm{E}-12$ & $1.02 \mathrm{E}-12$ & 34.8 \\
\hline Bare $^{*}$ & Creatinine & $1.00 \mathrm{E}-12$ & $6.54 \mathrm{E}-14$ & 6.50 \\
\hline Bare $^{*}$ & PEG-6000 & $1.90 \mathrm{E}-12$ & $4.71 \mathrm{E}-13$ & 24.8 \\
\hline Bare $^{*}$ & Albumin & $6.65 \mathrm{E}-14$ & $9.45 \mathrm{E}-15$ & 14.2 \\
\hline
\end{tabular}

* Hollow stent, $2 \%$ MV Alginate, $10 \% \mathrm{CaCl}_{2}, 60$ min crosslinking time.

+ Solid stent, $2 \%$ MV Alginate, $1.5 \% \mathrm{CaCl}_{2}, 15 \mathrm{~min}$ crosslinking time.

${ }^{* *}$ Hollow stent, $3 \% \mathrm{MV}$ Alginate, $10 \% \mathrm{CaCl}_{2}, 60$ min crosslinking time.

encapsulating colloidal particles, bacteria and nanoparticles [34], endothelial cells [35, 36] has also been proven as a result of biomarkers release. Albumin release from a 5 micron alginate coating adsorbed onto carbon nanotubes has also been characterized with $100 \%$ of the entrapped albumin released within $9 \mathrm{hrs}$ of hydration in cell culture media [37]. Mathematical models to describe the diffusion of solutes or drugs from a membrane have been reported in the literature, in both spherical [13] and cylindrical [19] forms. The method proposed by Kwok et al. involved a coupled set of partial differential equations with Dirichlet boundary conditions, while the proposed model in this study uses a single partial differential equation (the cylindrical diffusion equation) with a more complicated Neumann boundary condition. Experimental concentration values at the membrane surface were plotted against calculated concentration values by the numerical spherical model [13]. In this paper, the numerical model was solved by directly implementing the experimental data into the Neumann boundary condition. The development of drug-eluting stents has prompted quantitative analysis of drug diffusion behavior from mathematical models by Zhu [2] and McGinty [19] that also involve a coupled set of partial differential diffusion equations using a mix of both Dirichlet and Neumann boundary conditions, also in non-dimensionalized form. Analytical solutions have been developed fordrug diffusion through a 1D multilayer membrane structure $[19,38]$. However, once again no experimental data is available for the comparison of the prediction accuracy for the aforementioned cases.

Given the excellent agreement between the numerical and analytical models and the positive correlation of results into of the qualitative comparison of the cylindrical fibers to the previously wellcharacterized spherical alginate microcapsules, the use of the proposed diffusion models could be extended to a wide range of therapeutic scenarios previously cited.

\section{CONCLUSION}

In this study, alginate and chitosan were investigated for use as cylindrical stents for the purpose of potentially developing a biocompatible drug delivery system within a body canal or vessel. Hollow stents were made of porous, cross-linkable alginate and coated with chitosan to form a rigid biomembrane with tunable permeability. To understand the function of such a system and characterize diffusion behavior within a polymer membrane, a mathematical diffusion model was proposed. This model was a onedimensional cylindrical model based on Fick's diffusion equations and experimental parameters were set to match the initial condition and boundary conditions based on solute equilibration data obtained spectrophotometrically. Previously developed diffusion models have been used to quantitate diffusion in microcapsules with the method imparting a trial and error approach. In order to circumvent this over- 
determined mathematical system, diffusivity was approximated when the numerical model converged within a tight range of accuracy. The model itself has also been validated with an analytical model and residuals were plotted between the proposed model and the theoretical model with a maximum error of $4 \%$ between the models. The ability to determine quantitatively the diffusion profiles of a particular membrane type is an enabler for accurate functional assessment of drug delivery and tissue engineering systems, as well as non-medical/systems involving diffusion through a porous membrane. Future in-vitro studies will be conducted under physiological conditions at $37{ }^{\circ} \mathrm{C}$ to measure the enhancement in diffusion as a function of temperature. In addition, a larger number of MW markers will be used to regress the Stokes radius vs. the diffusivities in order to further validate the mathematical models. In parallel, the use of other non-destructive analytical methods namely fluorescence microscopy or fluorescence spectroscopy, characterized by a lower limit of detection than spectrophotometry [39] will be investigated using the aforementioned solutes, in order to deconvolute the sensitivity of the measurement techniques from the predictive accuracy of the models.

\section{ACKNOWLEDGEMENTS}

The authors would like to acknowledge the Davidson's College of Engineering Faculty Development grant "Inkjet Bioprinting", CSU Mini-Grant "Bio-Functionalized Resorbable Drug Eluting Stents" and C-SUPERB Joint Venture Grant "Bio-Printing of Mammalian Cells" for funding this effort.

\section{APPENDIX A}

$$
\begin{aligned}
& \text { Parameter = Definition } \\
& C_{m}=\text { solute concentration, }\left(\mathrm{mg} / \mathrm{mL} \text { or } \mathrm{kg} / \mathrm{m}^{3}\right) \\
& C_{b} \quad=\text { solute concentration of bulk solution at } \\
& \text { outer membrane surface, }(\mathrm{mg} / \mathrm{mL} \text { or } \\
& \mathrm{kg} / \mathrm{m}^{3} \text { ) } \\
& C_{0}=\text { Initial solute concentration, }(\mathrm{mg} / \mathrm{mL} \text { or } \\
& \mathrm{kg} / \mathrm{m}^{3} \text { ) } \\
& C_{e q}=\text { equilibrium solute concentration, }(\mathrm{mg} / \mathrm{mL} \\
& \text { or } \mathrm{kg} / \mathrm{m}^{3} \text { ) } \\
& V_{b} \quad=\text { volume of bulk solution }\left(\mathrm{mL}^{3}\right) \\
& V_{2} \quad=\text { stent volume }\left(\mathrm{V}_{2}=\pi \mathrm{r}_{2}^{2} \mathrm{~h} ; \mathrm{mL}^{3}\right)
\end{aligned}
$$

$$
\begin{aligned}
& A_{2}=\text { surface area of stent }\left(\mathrm{A}_{2}=2 \pi \mathrm{r}_{2} \mathrm{~h} ; \mathrm{m}^{2}\right) \\
& D \quad=\text { solute diffusivity through membrane } \\
& \left(\mathrm{m}^{2} / \mathrm{s}\right) \\
& r_{2}=\text { outer radius of stent }(\mathrm{m}) \\
& r_{1}=\quad \text { inner radius of stent }(\mathrm{m}) \\
& r \quad=\text { radial position }(\mathrm{m}) \\
& t \quad=\text { time }(\mathrm{s}) \\
& \tau=\mathrm{Dt} /\left(\mathrm{r}_{2}-\mathrm{r}_{1}\right)^{2} \text {, non-dimensionalized time } \\
& \xi \quad=\left(\mathrm{C}_{\mathrm{m}}-\mathrm{C}_{0}\right) /\left(\mathrm{C}_{\mathrm{b} 0}-\mathrm{C}_{0}\right), \quad \text { non-dimensionalized } \\
& \text { concentration } \\
& \xi_{b} \quad=\left(C_{b}-C_{0}\right) /\left(C_{b 0}-C_{0}\right), \quad \text { non-dimensionalized } \\
& \text { bulk concentration }
\end{aligned}
$$$$
X \quad=r /\left(r_{2}-r_{1}\right), \text { non-dimensionalized radial }
$$$$
\text { position }
$$$$
X_{1}=r_{1} /\left(r_{2}-r_{1}\right), \text { non-dimensionalized inner }
$$
radius

$X_{2}=r_{2} /\left(r_{2}-r_{1}\right)$, non-dimensionalized outer radius

$J_{0}(x) \quad=$ zeros of the Bessel function

$\mathrm{k}^{2}, \lambda=$ roots of the dimensionless Bessel differential equation

$A_{n} \quad=$ constant in the Bessel function to be solved

\section{REFERENCES}

[1] Park JH, Shin US, Kim HW. Alginate-microfibers produced by self-assembly in cell culture medium. Bull Korean Chem Soc 2011; 32 (2): 431-3. http://dx.doi.org/10.5012/bkcs.2011.32.2.431

[2] Zhu X, Pack DW, Braatz RD. Modelling intravascular delivery from drug-elutingstents with biodurable coating: investigation of anisotropic vascular drug diffusivity and arterial drug distribution. Comput Method Biomechs 2012; 1-12.

[3] Moroni L, Wijn JR, van Blitterswijk CA. Polymer hollow fiber three-dimensional matrices with controllable cavity and shell thickness. Biomaterials 2006; 27(5): 5918-26. http://dx.doi.org/10.1016/j.biomaterials.2006.08.015

[4] Tamayol A, Akbari M, Annabi N, Paul A, Khadamhosseini A, Juncker D. Fiber-based tissue engineering: progress, challenges, and opportunities. Biotechnology Advances 2012 [serial on the internet]. Available from:doi 10.1016/j.biotechadv.2012.11.007

[5] Zhang S, Liu T, Chen L, Ren M, Zhang B, Wang Z, et al. Bifunctionalpolyethersulfone hollow fiber with a porous, 
single-layer skin for use as a bioartificial liver bioreactor. $\mathrm{J}$ Mater Sci Mater Med 2012; 23: 2001-11. http://dx.doi.org/10.1007/s10856-012-4673-8

[6] Asthana A, Lee KH, Shun SJ, Perumal J, Butker L, Lee SH, et al. Bromo-oxidation reaction in enzyme-entrapped alginate hollow microfibers. Biomicrofluidics 2011 [serial on the internet]. Available from: http://dx.doi.org/10.10631/1.3605512.

[7] Wan J. Microfluidic-based synthesis of hydrogel particles for cell microencapsulation and cell-based drug delivery. Polymers 2012; 4(2): 1084-108. http://dx.doi.org/10.3390/polym4021084

[8] Luo Y, Lode A, Gelinsky M. Direct Plotting of ThreeDimensional Hollow Fiber Scaffolds Based on Concentrated Alginate Pastes for Tissue Engineering. AdvHealthc Mater 2012 [serial on the internet]. Available from: doi:10.1002/adhm.201200303

http://dx.doi.org/10.1002/adhm.201200303

[9] Amin S, Rajabnezhad S, Kohli K. Hydrogels as potential drug delivery systems. Sci Res Essays 2009; 3(11): 175-83.

[10] Takka S, Gürel A. Evaluation of Chitosan/Alginate Beads Using Experimental Design: Formulation and In vitro Characterization. AAPS PharmSciTech 2010; 11(1): 460-6. http://dx.doi.org/10.1208/s12249-010-9406-z

[11] Barralet JE, Wang L, Lawson M, Triffitt JT, Cooper PR, Shekton RM. Comparison of bone marrow cell growth on 2D and 3D alginate hydrogels. J Mater Sci Mater Med 2005; 16: 515-19.

http://dx.doi.org/10.1007/s10856-005-0526-z

[12] Mobed-Miremadi M, Asthi A, Nagendra R, Varma R. Alginate-Chitosan-Alginate Microcapsules for Oral Administration: 2009. Proceedings of the American Institute of Chemical Engineering Conference; Nashville, Tenessee, USA. Available from: www3.aiche.org/Proceedings/Extended Abstract.aspc?PaperID $=170186$

[13] Kwok WY, Kiparissides C, Yuet P, Harris JT, Goosen MFA. Mathematical modelling of protein diffusion in microcapsules: A comparison with results. Can J Chem Eng 1991; 69(1): 361-70.

http://dx.doi.org/10.1002/cjce.5450690144

[14] Goosen MFA. Fundamentals of Animal Cell Encapsulation and Immobilization. $1^{\text {st }}$ ed. Boca Raton: CRC Press 1992.

[15] Westrin B, Axelsson A, Zacchi G. Diffusion measurement in gels - A review. J Controlled Release 1994; 30: 189. http://dx.doi.org/10.1016/0168-3659(94)90025-6

[16] Wang N, Adams G, Buttery L, Falcone FH, Stolnik S. Alginate encapsulation technology supports embryonic stem cells differentiation into insulin-producing cells. J Biotechnol 2009; 144(4): 304-12.

http://dx.doi.org/10.1016/j.jbiotec.2009.08.008

[17] Yu G, Fan Y. Preparation of poly(D,L-lactic acid) scaffolds using alginate particles. J Biomater Sci - Polym Ed 2008; 19(1): 87-98. http://dx.doi.org/10.1163/156856208783227703

[18] Hsiong SX, Cooke PH, Kong H, Fishman ML, Ericsson M, Mooney DJ. AFM Imaging of RGD Presenting Synthetic Extracellular Matrix Using Gold Nanoparticles. Macromol Biosci 2008; 8(6): 469-77. http://dx.doi.org/10.1002/mabi.200700313

[19] McGinty S, McKee S. Modelling drug-eluting stents. Math Med Biol 2011; 28: 1-29. http://dx.doi.org/10.1093/imammb/dqq003

[20] Li RH, Altreuter DH, Gentile FT. Transport characterization of hydrogel matrices for cell encapsulation. Biotech Bioeng 1995; 50: 365-73. http://dx.doi.org/10.1002/(SICl)10970290(19960520)50:4<365::AID-BIT3>3.0.CO;2-J
[21] Russo R, Malinconico M, Santagata G. Effect of CrossLinking with Calcium Ions on the Physical Properties of Alginate FIms. Biomacromolecules 2007; 8(10): 3193. http://dx.doi.org/10.1021/bm700565h

[22] Flynn G, Yalkowsky S, Roseman T. Mass transport phenomena and models: theoretical concepts. J Pharm Sci 1974; 63(4): 479-10. http://dx.doi.org/10.1002/jps.2600630403

[23] Tanaka H, Matsumara M, Veliky IA. Diffusion characteristics of substrates in Ca-alginate gel beads. Biotech Bioeng 1984; 26(1): 53-8

http://dx.doi.org/10.1002/bit.260260111

[24] Carslaw H, Jaeger J. Conduction of Heat in Solids. $2^{\text {nd }}$ ed. Oxford: Oxford University Press 1959.

[25] Fick A. Úber diffusion. Ann Physik Leipzig 1855; 170: 59-86. http://dx.doi.org/10.1002/andp.18551700105

[26] Carnahan B, Luther HA, Wilkes JO. Applied Numerica Methods. New York: Wiley\&Son 1969.

[27] Crank J. The Mathematics of Diffusion, $2^{\text {nd }}$ ed. Oxford Clarendon Press 1975.

[28] Lakshminarayanakh N. Transport Phenomena in Membranes. New York: Academic Press 1969.

[29] Wang Q, Zhang N, Hu X, Yang J, Du Y Alginate/polyethylene glycol blend fibers and their properties for drug controlled release. J Biomed Mater Res A 2007; $82 \mathrm{~A}(1)$ : $122-28$. http://dx.doi.org/10.1002/ibm.a.31075

[30] Lin YS, Huang KS, Yang CH, Wang CY, Yang YS, Hsu HS, et al. Microfluidic Synthesis of Microfibers for MagneticResponsive Controlled Drug Release and Cell Culture. PLoS One 2012 [serial on the internet]. Available from: doi: 10.1371/journal.pone.0033184 http://dx.doi.org/10.1371/journal.pone.0033184

[31] Meyer U, Meyer T, Handschel J, W HP. Fundamentals of Tissue Engineering and Regenerative Medicine. $1^{\text {st }}$ ed. New York: Springer Verlag 2009.

http://dx.doi.org/10.1007/978-3-540-77755-7

[32] Mobed-Miremadi M, Asi B, Parasseril J, Wong E, Tat M, Shan Y. Comparative diffusivity measurments for alginatebased atomized and inkjet-bioprinted artificial cells using fluorescence microscopy. Artif Cells Nanomed Biotech 2012. [serial on the internet]. Available from: doi 10.3109/10731199.2012.716064. http://dx.doi.org/10.3109/10731199.2012.716064

[33] Andersen T, Strand BL, Formo K, Alsberg E, Christensen $\mathrm{BE}$. Alginates as biomaterials in tissue engineering. Carbohydrate Chem: Chem Biol Approach 2012; 37: 227-58. http://dx.doi.org/10.1039/9781849732765-00227

[34] Zheng SJ, Wu H. Generation of alginate microfibers with a roller-assisted microfluidic system. Lab Chip 2009; 9(7): 9961001.

http://dx.doi.org/10.1039/b813518e

[35] Takei T, Sakai S, Yokonuma T, ljima H, Kawakami K. Fabrication of artificial endothelialized tubes with predetermined three-dimensional configuration from flexible cell-enclosing alginate fibers. Biotech Prog 2007; 23(1): 1826. http://dx.doi.org/10.1021/bp060152j

[36] Lee KH, Shin SJ, Park Y, Leee SH. Synthesis of cell-laden alginate hollow fibers using microfluidic chips and microvascularized tissue-engineering applications. Small Volume 2009; 5: 1264-68. http://dx.doi.org/10.1002/smll.200801667

[37] Riggio C, Ciofani G, Raffa V, Bossi S, Micera S, Cushieri A. Polymeric Thin Film Technology for Neural Interfaces: review and Perspectives. In: Hashim AA editor. Polymeric Thin 
Films. Intech 2010. Available for free access at: http/www.intechopen.com/books/polymeric-thin-

films/polymeric-thin-film-technology-for-neural interfacesreview-and-perspectives.

[38] Pontrelli G, de Monte F. A multi-layer porous wall model for coronary drug-eluting stents. Int J Heat Mass Transfer 2010; 53(19-20): 3629-37.

http://dx.doi.org/10.1016/j.ijheatmasstransfer.2010.03.031
[39] Wehry EL. Molecular Fluorescence and Phosphorescence Spectrometry. In: Settle FA. Handbook of Instrumental Techniques for Analytical Chemistry. $1^{\text {st }}$ ed. National Science Foundation, Arlington, Virginia: Prentice Hall PTR (ECS Professional) 1997; pp. 507-536. 